\title{
Theoretical Research on Longitudinal Profile Design of Superhighways
}

\author{
Yongming He $\mathbb{D},,^{1,2}$ Yuting Song $\mathbb{D},{ }^{1}$ Yulong Pei $\mathbb{D}^{1},{ }^{1}$ Bin Ran $\mathbb{D}^{2,3}$ and Jia Kang $\mathbb{C}^{1}$ \\ ${ }^{1}$ School of Transportation, Northeast Forestry University, Harbin 150040, China \\ ${ }^{2}$ School of Civil Engineering, University of Wisconsin-Madison, Madison 57305, USA \\ ${ }^{3}$ Southeast University-University of Wisconsin Intelligent Network Transportation Joint Research Institute, Madison 53706, USA \\ Correspondence should be addressed to Yongming He; hymjob@nefu.edu.cn and Yulong Pei; peiyulong@nefu.edu.cn
}

Received 24 October 2020; Accepted 12 December 2020; Published 28 December 2020

Academic Editor: Ruimin Li

Copyright (c) 2020 Yongming He et al. This is an open access article distributed under the Creative Commons Attribution License, which permits unrestricted use, distribution, and reproduction in any medium, provided the original work is properly cited.

To improve driving safety on superhighways, longitudinal profile design parameters of a superhighway are calculated via force analysis while a car is driven on a slope. The calculations consider characteristics of drivers, cars, and roads. According to the vehicle type, design speed, and natural conditions, the maximum longitudinal slope of a superhighway is calculated and compared with those of an ordinary superhighway and high-speed railway. Based on analysis of the vehicle climbing performance, braking performance, and driver visual characteristics, the maximum and minimum slope lengths of a superhighway are calculated. By analyzing the elements of vertical curves, the minimum radius and minimum length of the vertical curves of a superhighway are calculated by considering factors such as mitigating the impact at the slope bottom, driving at night, and driving time along vertical curves. Analysis and calculation results show that when the maximum longitudinal slope is $2.50 \%, 2.25 \%$, and $2.00 \%$, the minimum slope length is $450 \mathrm{~m}, 400 \mathrm{~m}$, and $350 \mathrm{~m}$, respectively, and the minimum vertical curve length is $145 \mathrm{~m}, 130 \mathrm{~m}$, and $115 \mathrm{~m}$, respectively, and the superhighway travel requirements can be satisfied at speeds of $180 \mathrm{~km} / \mathrm{h}, 160 \mathrm{~km} / \mathrm{h}$, and $140 \mathrm{~km} /$ h, respectively.

\section{Introduction}

In more than 10 countries in Europe, such as France and the Netherlands, the maximum speed limit on highways is $130 \mathrm{~km} / \mathrm{h}$ [1], and in Texas, USA, the maximum speed limit is $137 \mathrm{~km} / \mathrm{h}$ (85 mile/h) [2]; in Italy, it is $140 \mathrm{~km} / \mathrm{h}$ [3], while in Germany, there is no maximum speed limit on some highways [4]. The Highway Engineering Design Guidelines (Draft) published in 1951 stipulated for the first time that the maximum design speed of highways in China was $120 \mathrm{~km} / \mathrm{h}$, and it has been used ever since [5].

More than 60 years have passed, and the technologies of highway construction and automobile performance have greatly improved in China, and it is possible to construct superhighways with a design speed exceeding $120 \mathrm{~km} / \mathrm{h}$. Construction of the first superhighway in China began in 2018, which is the Hang-Shao-Yong Highway, from Hangzhou to Ningbo via Shaoxing, and it will open in 2022 in time for the opening of the Asian Games in Hangzhou. It took only two years after the definition of a superhighway was proposed by the current authors in 2016 [6]. In March 2019 , construction of the second superhighway with a special traffic lane for automatic driving started, which is the JingXiong Highway, from Beijing to Xiong'an. The development speed of the superhighway is much higher than expected [7].

At present, the superhighway faces two major problems, safety and economy, especially safety is very important. To improve highway safety and efficiency, we established a speed guidance system via the experimental and simulation methods. The results show that the highway speed guidance system can effectively improve safety and driving conditions [7]. Considering that the speed limit on highways in many countries exceeds $120 \mathrm{~km} / \mathrm{h}$, automobile and highway construction technologies in China have attained great progress, and the concept of a superhighway was proposed for the first time by the current authors. In the same paper, 
we defined different technical grades of a superhighway and demonstrated the feasibility and necessity of the various grades [6]. Subsequently, we published several papers after conducting in-depth research on superhighway safety, economy, and traffic capacity. The safety of superhighways was demonstrated from three perspectives: automobile technology, highway technology, and foreign experience of superhighway safe operation [8]. To evaluate the economic efficiency of superhighways, we compared the cost of traveling by superhighways with the cost of traveling by bus, train, and airplane. The results show that the cost of traveling by superhighways for a single person is between 0.29 and 0.47 yuan $/ \mathrm{km}$, which is less expensive than traveling by busses but more expensive than traveling by trains and airplanes [9]. To study the capacity of superhighways, we compared it with that of an ordinary highway. The results show that optimizing the design speed of a superhighway does not increase the traffic capacity, but special highway lanes for automatic driving vehicles can enhance the design speed and also increase the traffic capacity [10].

Due to our research, scholars began to study superhighways. Chen and Peng aimed at the characteristic advantages and disadvantages, opportunities, and threats due to the external environment of a superhighway during the construction and operation management periods and provided suggestions for the future development of superhighways by using strengths, weaknesses, opportunities, and threats (SWOT) analysis [11]. Zhao et al. proposed stringent safety requirements for superhighways based on an investigation of the most common problems in existing highway horizontal curve design. Starting from meeting safety requirements, they established an obstacle identification model for the geometric analysis of flat curves and calculated the safety limit of the horizontal curve radius of superhighways, which provided the basis for the study of superhighways and their flat curves [12].

There are many studies on highways (expressway and freeway) in China and abroad, especially those related to safety. Chen et al. studied single-vehicle (SV) accidents and multivehicle (MV) accidents in adverse driving conditions, such as inclement weather and/or complex terrain [13]. Feng and Chen. studied the relationship between road traffic accidents and road geometric feature [14]. However, there is almost no separate research on highways with a design speed exceeding $120 \mathrm{~km} / \mathrm{h}$. The previous studies related to safety mainly examined driving while fatigued speeding, overloaded driving, brake failures, tire burst, geometric design, and safety facilities. Therefore, in this paper, the geometric design of highways is investigated.

Zhang et al. selected seven countries to conduct a comparative study of highway design parameters to illustrate the similarities and differences. They found that there were many similarities in terms of the fundamental design principles. However, differences were observed as well, such as the vertical radius, grade, and so on. Unexpectedly, the design standards in China were far more stringent than those in the selected countries although the design speeds on the highways in these countries exceeded $120 \mathrm{~km} / \mathrm{h}$ [15]. Fambro et al. presented a new model for determining stopping sight distance requirements for the geometric design of highways. This model is based on parameters describing the driver and vehicle capabilities that can be validated with field data and can result in safe driving behavior. The recommended values are attainable by most drivers, vehicles, and roadways. This model defines stopping sight distances, sag vertical curve lengths, and lateral clearances that are between the current minimum and desired requirements and exceed the vertical curve lengths, which are shorter than the current minimum requirements [16]. Kang et al. proposed separate computational methods for evaluating fuel efficiency, sight distance deficiencies, and expected accident costs for a given highway alignment, depending on detailed geometric characteristics. A case study was presented to demonstrate the effectiveness of the developed methods [17]. Porter et al. proposed a conservative approach to establish geometric design criteria, which were used to address the ranges of the driver and vehicle, roadway conditions, and capabilities that must be considered in design. They established a relationship between the road geometry and operating speed and studied the degree to which the road geometry influences the driving speed, the influence of the road geometry on safety, and the potential impacts on large vehicles [18]. Castro and De Santos-Berbel examined the use of a geographic information system (GIS) for an integrated analysis, taking into account two accidentrelated factors: the design consistency (DC) (based on the vehicle speed) and the available sight distance (ASD) (based on visibility). Their results showed that DC and ASD were related to crashes in approximately $4 \%$ of the studied cases [19]. Dong et al. studied the effects of highway geometric design features on the frequency of truck-involved crashes. They found that the zero-inflated negative-binomial (ZINB) model has desirable distribution properties to describe the relationship between large truck-involved crashes and geometric design features in terms of a better goodness of fit, more precise parameter estimates, more identified significant factors, and improved prediction accuracy [20].

The studies above have played a role in improving highway safety. However, the longitudinal profile of superhighways was not considered in these studies. Therefore, based on force analysis while operating a vehicle on a slope, in this paper, the maximum longitudinal slope of superhighways is calculated according to the vehicle type, design speed, and natural conditions and compared with the maximum longitudinal slopes of ordinary highways and high-speed railways; based on analysis of the vehicle braking performance and driver visual characteristics, the maximum and minimum slope lengths of superhighways are obtained; based on analysis of elements of vertical curves, the minimum radius and minimum length of vertical curves of superhighways are calculated, taking into account factors such as mitigating the impact, illuminated distance, sight distance, and driving time along vertical curves.

\section{Overview of Superhighways}

2.1. Background of Superhighways. The construction speed and quality of infrastructure projects such as highways and railways in China have attracted worldwide attention and are 
considered construction super projects. By the end of 2018, the total highway length in China had exceeded $140,000 \mathrm{~km}$, thereby ranking first in the world for eight consecutive years and far ahead compared with other countries. The starting length of its high-speed railways was $29,000 \mathrm{~km}$, which accounted for more than $60 \%$ of the total length of highspeed railways worldwide.

From 1997 to 2007, the railways in China have experienced six speed increases, and the average speed increased from $48.1 \mathrm{~km} / \mathrm{h}$ to $70.18 \mathrm{~km} / \mathrm{h}$ [21]; in 2008 , the first highspeed railway from Beijing to Tianjin with a design speed of $350 \mathrm{~km} / \mathrm{h}$ was opened [22]; in 2006, the first Maglev line in China was launched, with a running speed of $430 \mathrm{~km} / \mathrm{h} \mathrm{[23].}$ Railways have undergone leapfrog breakthroughs in both length and operation speed.

The total length of the highways in China is also constantly breaking historical records. The starting length is already ranked first in the world, and a number of superprojects have been delivered. For example, of the ten longest sea-crossing bridges in the world, five are in China, and the Hong Kong-Zhuhai-Macao Bridge is the longest [24]. However, the maximum design speed limit on the highways in China has never been optimized, which has remained $120 \mathrm{~km} / \mathrm{h}$. It has not changed in 68 years, and there is no relevant research on increasing the speed limit on highways.

The development of high-speed railways in China has provided valuable experience for the construction of superhighways. The safe operation of highways in foreign countries with a design speed limit exceeding $120 \mathrm{~km} / \mathrm{h}$ has provided confidence for the safe operation of superhighways in China. Therefore, the authors proposed the idea of superhighways.

2.2. The Definition of a Superhighway. A superhighway is designed to be a highway with a design speed higher than $120 \mathrm{~km} / \mathrm{h}$. The superhighway is different from an ordinary highway. To ensure the safety of a superhighway, the pavement of a superhighway is flatter, the route is smoother, and the facilities are more comprehensive [25].

Since the definition of a superhighway was established, it has been approved by many professors at various universities, such as Tongji University, Southeast University, and Chang'an University, and has aroused extensive interest from scholars attending the First World Transportation Conference in June 2017. In January 2018, the report entitled "Feasibility Study of Superhighways Based on Expenses" at the Donglin-Tongji Academic Conference resulted in a lively discussion among participating scholars. At present, the Intelligent Network and Transportation Joint Research Institute of the Southeast University-University of Wisconsin is engaged in research on autonomous driving lanes based on vehicle-road collaboration technology and has applied for a number of patents in the United States and China, which provides technical support for the development of superhighways.

2.3. Classification of a Superhighway. While defining a superhighway for the first time, the author also proposed different technical grades of superhighways and the maximum design speed. The proposed technical grades of superhighways are listed in Table 1.

Considering safety and economic problems, after several rounds of expert peer review, the classification speed was considered too high, and so the classification and design speed of superhighways were adjusted. The adjusted technical grades and maximum design speed of superhighways are summarized in Table 2 .

While defining different grades of superhighways, the designated vehicle types, construction modes, and expected construction time were proposed for all grades. A comparison of the different superhighway grades is provided in Table 3.

The above vehicle types, construction modes, and expected construction times of all superhighway grades were only preliminary assumptions when the definition of a superhighway was first introduced, and there will be large discrepancies during the actual development. For example, we had expected that superhighways of grade I would be built in 15 years, but it took only two years after first defining superhighways. With the transformation of highway construction from high speed to high quality and the rapid development of automatic driving technology, superhighway construction at all levels will soon become reality.

\section{Design of the Longitudinal Gradient of a Superhighway}

\subsection{Analysis of Vehicle Driving Force}

3.1.1. Slope Resistance of a Car. When a car is driven on a slope, the force component of gravity parallel to the road surface is called slope resistance, as shown in Figure 1.

As seen from the figure above, the slope resistance of a car driven on a slope can be calculated with the following equation:

$$
p_{i}= \pm G_{a} \cdot \sin \alpha
$$

where $P_{i}$ is the slope resistance, $\alpha$ is the road slope angle, "+" means that the car is driven up the slope and $P_{i}$ is opposite to the direction of the car, which inhibits driving, and "-" indicates that the car is driven down the slope and $P_{i}$ is in the same direction as the car, which accelerates the car [26].

The steepness of the longitudinal slope of a highway is usually expressed as slope $i$, which is the percentage of the vertical height of the slope to its horizontal length. Therefore, slope $i$ can be expressed as the following equation:

$$
i=\frac{h}{s}=\tan \alpha .
$$

As the slope angle $\alpha$ of the longitudinal slope of a superhighway does not exceed $3^{\circ}$, this value can be substituted in $\tan \alpha$ and $\sin \alpha$. Therefore, the slope resistance can be expressed as the following equation:

$$
P_{i}= \pm G_{a} \tan \alpha= \pm G_{a} i .
$$


TABLE 1: Novel classification of highways.

\begin{tabular}{|c|c|c|c|c|c|c|c|c|c|c|c|c|}
\hline \multirow{2}{*}{ Grade } & \multicolumn{9}{|c|}{ Superhighway } & \multirow{2}{*}{\multicolumn{3}{|c|}{ Ordinary highway }} \\
\hline & \multicolumn{3}{|c|}{ Grade III } & \multicolumn{3}{|c|}{ Grade II } & \multicolumn{3}{|c|}{ Grade I } & & & \\
\hline Design speed $/ \mathrm{km} / \mathrm{h}$ & 240 & 220 & 200 & 200 & 180 & 160 & 160 & 140 & 120 & 120 & 100 & 80 \\
\hline
\end{tabular}

TABLE 2: Adjusted classification of highways after peer review.

\begin{tabular}{|c|c|c|c|c|c|c|c|c|c|c|c|c|}
\hline \multirow{2}{*}{ Grade } & \multicolumn{9}{|c|}{ Superhighway } & \multirow{2}{*}{\multicolumn{3}{|c|}{ Ordinary highway }} \\
\hline & \multicolumn{3}{|c|}{ Grade III } & \multicolumn{3}{|c|}{ Grade II } & \multicolumn{3}{|c|}{ Grade I } & & & \\
\hline Design speed $/ \mathrm{km} / \mathrm{h}$ & 180 & 160 & 140 & 160 & 140 & 120 & 140 & 120 & 100 & 120 & 100 & 80 \\
\hline
\end{tabular}

TABle 3: Comparison of the different superhighway grades.

\begin{tabular}{lccc}
\hline Grade & Vehicle type & Construction mode & Expected construction time \\
\hline Grade I & Cars and trucks & Retrofitting existing highways & 15 years \\
Grade II & Only for cars & According to passenger-dedicated railway specifications & 30 years \\
Grade III & Only for autonomous vehicles & According to high-speed railways & $40-50$ years \\
\hline
\end{tabular}

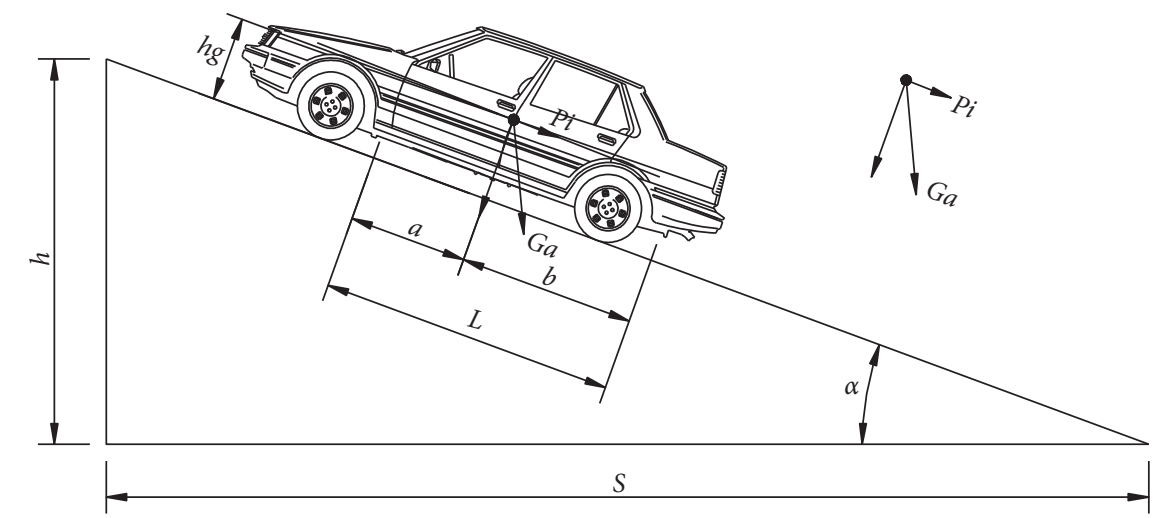

FIGURE 1: Force analysis while driving on a slope.

3.1.2. Necessary Conditions for Driving. Driving the car on the slope is not only affected by the slope resistance $P_{i}$ but also by the rolling resistance $P_{f}$, air resistance $P_{w}$, and inertia resistance $P_{j}$.

To enable the car to move forward, the traction force of the car must be equal to the sum of all the resistance forces encountered when the car moves, which is expressed in the following equation:

$$
P_{t}=P_{f} \pm P_{i}+P_{w} \pm P_{j}
$$

Substituting the previous relevant equation into equation (4), the following equation is then obtained:

$$
\frac{M_{e} \cdot i_{k} \cdot i_{0} \cdot \eta_{m}}{r_{k}}=G_{a} f \pm G_{a} i+\frac{K F V^{2}}{13} \pm \delta \frac{G_{a}}{g} \cdot \frac{\mathrm{d} v}{\mathrm{~d} t}
$$

where "+" before $P_{i}$ means upslope and "-" means downslope; also, "+" before $P_{j}$ indicates acceleration and "-" indicates deceleration. $P_{f}$ and $P_{w}$ are always positive.

Equations (4) and (5) are called traction balance equations, that is, the traction $P_{t}$ of the car must be equal to the sum of all the resistance forces. The above conditions are necessary for the car to move forward, also referred to as the driving conditions.

3.1.3. Sufficient Conditions for Driving. The traction force of a car is the same as the horizontal reaction force of the road exerted on the wheels, and the horizontal reaction force of the road exerted on the wheels is restricted by the adhesion conditions between the tires and the road. If the friction between the tires and the road is very small, it cannot provide enough horizontal traction and the tires will slip on the road surface or idling can even occur. Therefore, the traction force of a car must be lower than or equal to the friction force between the tires and the road; that is, it should be lower than the limiting value of the horizontal reaction force exerted by the road on the tires, which can be expressed as the following equation:

$$
P_{t} \leq G \cdot \phi,
$$

where $G$ is the load of the wheels, and for an all-wheel drive car, it is the total weight of the car, while for a rear-wheel drive car, it is lower than the total weight of the car. The value range of regular cars is from $0.5 G_{a}$ to $0.65 G_{a}$ and that 
of heavy vehicles is from $0.65 G_{\mathrm{a}}$ to $0.8 G_{a}$. In addition, $\phi$ is the coefficient of friction between a tire and the road.

Equation (6) describes the sufficient condition to drive a vehicle, also known as the adhesion condition. The combination of equations (4) and (5) defines the sufficient and necessary conditions for automobile driving, also known as the driving and adhesion conditions of automobile movement:

$$
P_{t}=P_{f} \pm P_{i}+P_{w} \pm P_{j} \leq G \phi .
$$

\subsection{Maximum Longitudinal Slope of a Superhighway}

3.2.1. The Basis for Determining the Maximum Longitudinal Slope. Vehicle type: The power performance and braking performance of different vehicle types, such as passenger vehicles, cargo vehicles, and other different types of vehicles, are quite different. Therefore, the design requirements on the maximum longitudinal slopes of highways are also different.

Design speed: According to analysis results of the dynamic characteristic curves of vehicles, the climbing ability is inversely proportional to the driving speed. The faster a vehicle is driven, the lower its climbing ability is. Therefore, when determining the maximum longitudinal slope, a certain driving speed must be ensured.

Natural conditions: The altitude, climate, and terrain of the area where the highway is located will also affect the driving conditions and climbing ability of cars.

3.2.2. Formulation Method of the Maximum Longitudinal Slope Standard. When defining the maximum longitudinal slope of a highway, the Highway Engineering Technical Standard mainly considers the climbing ability of vehicles in the upslope direction, the safety of vehicles in the downhill direction, as well as the driving requirements of vehicles in the uphill and downhill directions when roads are slippery due to rain and snowfall.

The maximum longitudinal slopes of highways with different design speeds stipulated in the highway engineering technical standards are listed in Table 4.

In actual highway route design, the primary basis for determining the maximum longitudinal slope is the maximum climbing ability of vehicles, and the maximum climbing ability is mainly determined by calculations, research, and experiments.

The calculation method relies on the dynamic performance diagram of a vehicle. According to the principle of constant-speed climbing, the calculation method is based on the vehicle type, speed, and load when the vehicle is driven in the upslope direction.

The investigation method is aimed at determining the maximum longitudinal slope value by investigating the driving conditions of automobiles on slopes and analyzing survey data of slope sections. The test method selects the design vehicle as the experimental object, drives on different longitudinal slopes at different speeds, and determines the appropriate longitudinal slope according to the parameters of the vehicle speed and slope length of the designed route.
3.2.3. Maximum Longitudinal Slope of Superhighway. For a superhighway, the determination of its maximum longitudinal slope needs to consider the climbing ability of a car in the upslope direction and its stability in the downslope direction. However, these longitudinal slope considerations do not necessarily pertain to livestock vehicles or rain, snow, fog, and other special weather conditions, and special requirements can be achieved by adjusting the speed limit.

The Design Standard for High-speed Railways and the Design Standard for Intercity Railways stipulate that the maximum gradients of the main lines of high-speed and intercity railways shall not be higher than $2.0 \%$. Under difficult conditions, the maximum gradient shall not be higher than 3.0\% after technical and economic review. At the same time, the Design Standard for Intercity Railway stipulates that the maximum slope of intercity railway lines shall not be higher than 3.0\% and shall not be higher than 3.5\% under difficult conditions. The maximum limits of the longitudinal slope specified in railway route design standards are summarized in Table 5.

Therefore, according to the current maximum longitudinal slopes of highways at all levels, as well as the vehicle climbing and braking performance, the maximum longitudinal slope of a superhighway is calculated according to the relevant railway specifications, as listed in Table 6 .

As indicated by Tables 4 and 6, when the design speed is $120 \mathrm{~km} / \mathrm{h}$ and $100 \mathrm{~km} / \mathrm{h}$, the maximum longitudinal slope of a superhighway is the same as that of an ordinary superhighway.

\subsection{Minimum Longitudinal Slope of a Superhighway}

3.3.1. The Basis for Determining the Minimum Longitudinal Slope. To ensure safety and comfort while driving a car at the design speed, it is generally required that the design road slope is as flat as possible. However, in order to ensure that rainwater and slope seepage can be discharged in time and prevent moisture from infiltrating into the roadbed and affecting the stability of the roadbed, a longitudinal slope higher than $0.3 \%$ should be established. In actual engineering design, a longitudinal slope higher than $0.5 \%$ should generally be adopted.

3.3.2. Minimum Longitudinal Slope of a Superhighway. The design standard of a superhighway is much more stringent than that of an ordinary highway, and its drainage system should be optimal. In the case of an optimal drainage system design such as bridges and tunnels, the minimum longitudinal slope is generally not considered. However, the minimum longitudinal slope in excavated or other sections with poor drainage should be the same as that of an ordinary highway. The longitudinal slope should be higher than $0.3 \%$. If conditions permit, the longitudinal slope should be higher than $0.5 \%$ as frequently as possible.

\section{Slope Length Limit of a Superhighway}

4.1. Minimum Slope Length Limit of a Superhighway. The longitudinal slope length of a highway refers to the distance 
TABLE 4: Maximum longitudinal grades of highways.

\begin{tabular}{lccccccc}
\hline Design speeds $(\mathrm{km} / \mathrm{h})$ & 120 & 100 & 80 & 60 & 40 & 30 & 20 \\
\hline Maximum longitudinal slopes (\%) & 3.00 & 4.00 & 5.00 & 6.00 & 7.00 & 8.00 & 9.00 \\
\hline
\end{tabular}

TABLE 5: Maximum slope of railways (unit: \%).

\begin{tabular}{|c|c|c|c|c|c|c|c|}
\hline \multirow{2}{*}{\multicolumn{2}{|c|}{ Railway grades }} & \multicolumn{3}{|c|}{ I } & \multicolumn{3}{|c|}{ II } \\
\hline & & Plains & Hills & Mountains & Plains & Hills & Mountains \\
\hline \multirow{2}{*}{ Traction types } & Electrical motor & 0.60 & 1.20 & 1.50 & 0.60 & 1.50 & 2.00 \\
\hline & Internal combustion engine & 0.60 & 0.90 & 1.20 & 0.60 & 0.90 & 1.50 \\
\hline
\end{tabular}

Note. Railways of grade I: passenger train running speeds of $160 \mathrm{~km} / \mathrm{h}, 140 \mathrm{~km} / \mathrm{h}$, and $120 \mathrm{~km} / \mathrm{h}$; railways of grade II: passenger train running speeds of $120 \mathrm{~km} / \mathrm{h}, 100 \mathrm{~km} / \mathrm{h}$, and $80 \mathrm{~km} / \mathrm{h}$.

TABle 6: Maximum slope of superhighways (unit: \%).

\begin{tabular}{llllll}
\hline Design speeds $(\mathrm{km} / \mathrm{h})$ & 180 & 160 & 140 & 120 & 100 \\
\hline Maximum slopes $(\%)$ & 2.00 & 2.25 & 2.50 & 3.00 & 4.00 \\
\hline
\end{tabular}

between two adjacent slope change points along a longitudinal section. The maximum longitudinal slope length should be limited in order to prevent cars from decelerating too much in the upslope direction and braking from occurring too long in the downslope direction. To ensure that fewer longitudinal changes occur when a vehicle is driven, it is necessary to limit the minimum slope length of a highway. Therefore, the superhighway slope length limit is similar to that of a normal highway slope length, including the minimum and maximum slope length limits.

If there are too many slope change points along a longitudinal section of a superhighway, vertical fluctuations will be frequently observed from the visual point of view, similar to traveling between peaks and valleys. From the perspective of the body sensation of a driver, numerous vehicle undulations will seriously affect driving comfort, and the higher the speed is, the more notable the effect will be felt. The design speed of a superhighway is much higher than that of highways of all current grades; therefore, the minimum slope length needs to be more strictly limited. When the gradient difference is large, vertical fluctuation changes occur frequently, which easily results in a limited visual range and line of sight interruptions, thereby affecting driving safety and comfort. Based on the geometric properties of the longitudinal profile of a superhighway, the length between adjacent slope change points should not be very short, and the shortest distance should be longer than the tangent line of the adjacent vertical curve. Therefore, the longitudinal slope of a superhighway should be defined considering the visibility, comfort, and geometric line continuity.

The Technical Standard for Highway Engineering suggests that the minimum longitudinal slope length should not be shorter than the distance traversed by a car traveling at the design speed for 9-15 seconds. On highways, driving for 9 seconds meets the visual and geometric layout requirements. To satisfy these vision and linear layout requirements on low-speed highways, a longer duration is needed. The Technical Standard for Highway Engineering defines the minimum slope length of highways as a function of the design speed, as listed in Table 7.

The design codes of high-speed and intercity railways also restrict the minimum slope lengths of railway routes. To reduce the longitudinal slope, increasing the slope length as much as possible is adopted in railway route design. According to the relevant railway design regulations, the slope lengths of railway main lines should be designed as long as possible to reduce the slope. The minimum slope length in railway route design should be calculated and determined according to equation (8) and be a multiple of $50 \mathrm{~m}$. Under general conditions, the length shall not be less than $400 \mathrm{~m}$, while under difficult conditions, the length shall not be shorter than $200 \mathrm{~m}$.

$$
L_{p}=\frac{\left(\Delta i_{1}+\Delta i_{2}\right)}{2} \times R_{s h}+(0 \sim 0.4) \mathrm{V}
$$

where $L_{p}$ is the minimum slope length, $\Delta i_{1}$ and $\Delta i_{2}$ are the adjacent slope differences at both ends of the slope section, and $V$ is the design speed, in $\mathrm{km} / \mathrm{h}$. The coefficient of $V$ is usually 0.4 under general conditions and 0 under difficult conditions. $R_{s h}$ is the radius of the vertical curve.

According to the calculation method and results provided in the Technical Standard for Highway Engineering and referring to relevant specifications of railway design, the calculation results of the minimum slope length of superhighways are listed in Table 8.

As seen from Tables 7 and 8, when the design speed is $120 \mathrm{~km} / \mathrm{h}$ and $100 \mathrm{~km} / \mathrm{h}$, the minimum slope length limit of the superhighway is the same as that of the ordinary superhighway.

4.2. Maximum Slope Length Limit of a Superhighway. A superhighway slope length that is too short adversely impacts driving safety and comfort, and a slope that is too steep is also bad for driving. The design speed of superhighways is usually higher than $120 \mathrm{~km} / \mathrm{h}$. When the longitudinal slope is large, the slope resistance that needs to be overcome by high-speed driving and climbing will increase exponentially, and the engine will operate under a full load. If the slope length is too long, the engine may overheat, affecting the service life of the engine and even causing engine damage. When driving down a long slope, due to the long braking 
TABle 7: Current minimum length of highway slopes.

\begin{tabular}{lccccccc}
\hline Design speed $(\mathrm{km} / \mathrm{h})$ & 120 & 100 & 80 & 60 & 40 & 30 & 20 \\
\hline Maximum slope $(\%)$ & 300 & 250 & 200 & 150 & 120 & 100 & 60
\end{tabular}

TABle 8: Minimum lengths of superhighway slopes.

\begin{tabular}{llllll}
\hline Design speed $(\mathrm{km} / \mathrm{h})$ & 180 & 160 & 140 & 120 & 100 \\
\hline Maximum slope (\%) & 450 & 400 & 350 & 300 & 250 \\
\hline
\end{tabular}

times, brake friction plates can become overheated, which easily results in brake failure affecting driving safety.

The service targets of superhighways of grade I include busses and trucks in addition to cars. While they are driving on a slope, their speed differences are obvious. The larger the speed difference is, the greater the impacts on the capacity and safety of superhighways are, and therefore, the longitudinal slope length of a superhighway must be limited.

In China, much investigation and experimental research have been carried out when formulating the limit standard of highway longitudinal slope lengths at all levels. On this basis, the Technical Standard for Highway Engineering stipulates the maximum slope length of highways as a function of the design speed, as listed in Table 9.

Based on D-series high-speed trains, the Design Standard for High-speed Railways has defined the maximum lengths of different design longitudinal slopes, as summarized in Table 10.

According to the highway longitudinal slope length at all levels and the maximum longitudinal slope of superhighways provided in the Technical Standard for Highway Engineering, based on relevant railway design specifications, the maximum slope length of superhighways is calculated and listed in Table 11.

The maximum length of a superhighway mainly considers that vehicles should not decelerate too much when driving upslope, while driving in the downslope direction is much less considered. For example, if fewer trucks are expected on superhighways of grade I, brake failure while driving downslope is handled as is done for ordinary highways. Superhighways of grades II and III are only for cars, and all longitudinal slopes are designed to be lower than $2 \%$. To inhibit acceleration when driving downslope, the vehicle speed should be reduced only by wind and rolling resistance, and the brake system will not fail due to a long braking distance.

\section{Vertical Curves of Superhighways}

5.1. The Role of the Vertical Curve. The design slope line along the longitudinal profile of a superhighway is composed of many individual lines, which causes vehicles to experience shocks and turbulence. When encountering the long slope section of a convex turning point, the lines of sight of drivers are easily impeded, and when the speed is high, a feeling of weightlessness can be generated at the top of a slope. When encountering a concave turning point, as a result of the action of centrifugal forces, passengers can feel weighted
TABLE 9: Maximum length of a highway slope (unit: m).

\begin{tabular}{lcccccccc}
\hline Design speeds $(\mathrm{km} / \mathrm{h})$ & 120 & 100 & 80 & 60 & 40 & 30 & 20 \\
\hline & 3 & 900 & 1000 & 1100 & 1200 & - & - & - \\
& 4 & 700 & 800 & 900 & 1000 & 1100 & 1100 & 1200 \\
& 5 & - & 600 & 700 & 800 & 900 & 900 & 1000 \\
Longitudinal & 6 & - & - & 500 & 600 & 700 & 700 & 800 \\
slope (\%) & 7 & - & - & - & - & 500 & 500 & 600 \\
& 8 & - & - & - & - & 300 & 300 & 400 \\
& 9 & - & - & - & - & - & 200 & 300 \\
& 10 & - & - & - & - & - & - & 200 \\
\hline
\end{tabular}

TABLe 10: Maximum slope length of high-speed railways.

\begin{tabular}{lcccc}
\hline Maximum design slope (\%) & 1.5 & 2.0 & 2.5 & 3.0 \\
\hline Maximum slope length $(\mathrm{m})$ & 10000 & 6000 & 4000 & 3000 \\
\hline
\end{tabular}

TABLE 11: Maximum slope length (unit: $\mathrm{m}$ ).

\begin{tabular}{ccccccc}
\hline Design speeds $(\mathrm{km} / \mathrm{h})$ & 180 & 160 & 140 & 120 & 100 \\
\hline & 0.5 & - & - & - & - & - \\
& 1.0 & 1000 & - & - & - & - \\
& 1.5 & 900 & 1000 & 1100 & - & - \\
Longitudinal slope (\%) & 2.0 & 800 & 900 & 1000 & 1100 & 1200 \\
& 2.5 & - & - & 900 & 1000 & 1100 \\
& 3.0 & - & - & - & 900 & 1000 \\
& 4.0 & - & - & - & 700 & 900 \\
\hline
\end{tabular}

down and uncomfortable, and the springs below the vehicle chassis may become overloaded at the same time. Therefore, in order to make the longitudinal profile of a superhighway smoother and to ensure the stability, safety, and comfort of drivers, it is necessary to establish smooth vertical curves at longitudinal slope change points along the longitudinal profile and connect adjacent straight slope sections naturally.

The transition point of a vertical curve connected to a convex curve is called a convex vertical curve, and when connected to a concave curve, it is a concave vertical curve. Convex and concave vertical curves are shown in Figure 2.

In the figure, $\omega$ is the change slope angle, and its value is equal to the algebraic difference between the longitudinal slopes of two adjacent slope sections. That is, $\omega=i_{2}-i_{1}$, where $i_{2}$ and $i_{1}$ are the design longitudinal slopes of two adjacent straight-line slope sections (expressed as a decimal), with "+" indicating the uphill direction and "-" the downhill direction. When $\omega$ is larger than 0 , the vertical curve is concave, and when $\omega$ is smaller than 0 , the vertical curve is convex.

At the slope top of a superhighway, in order to eliminate the turning line of the longitudinal slope, the line is made rounder, and to ensure an unobstructed line of vision of drivers, a convex vertical curve must be established, as shown in Figure 3.

To make the line smoother and reduce bumps and vibrations, concave vertical curves must be located at the bottom of superhighway slopes. 


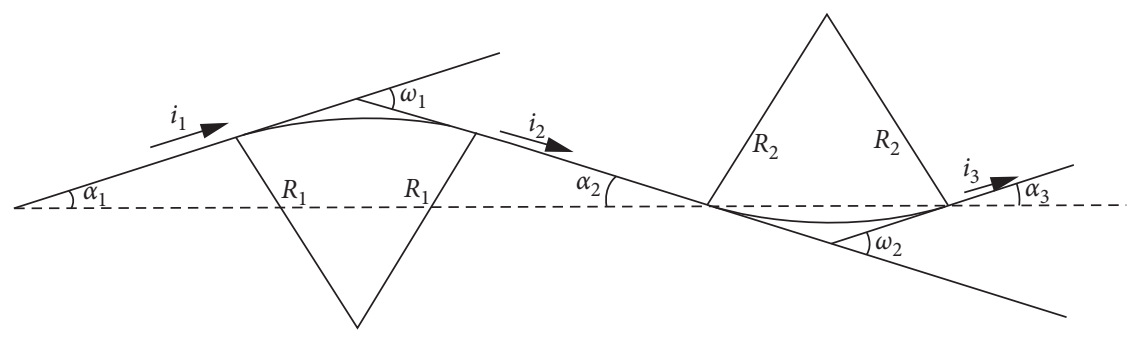

FIgURE 2: Convex and concave vertical curves.

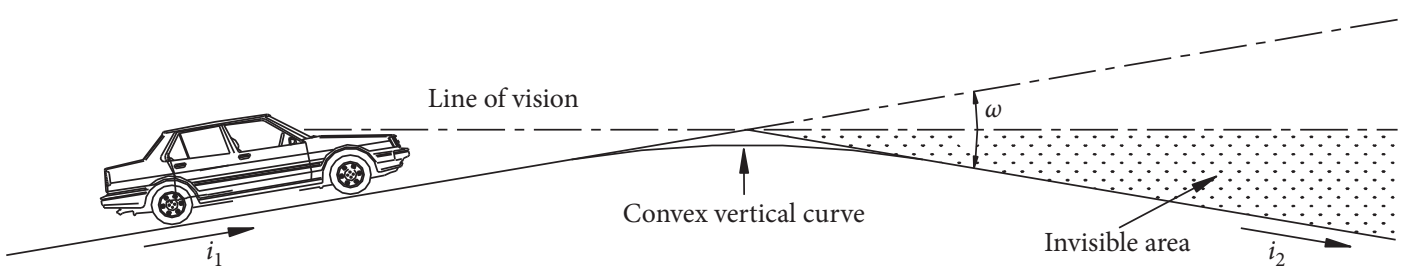

FIgURE 3: Convex vertical curve and change slope angle.

5.2. Vertical Curve Element Analysis and Calculation. In China, the Highway Route Design Standard (JTG d20-2006) requires that parabolic or circular curves should be implemented as vertical curves (in Figure 2). At the same time, the standard also specifies that because the slope difference before and after a vertical curve is small, a parabolic curve has a very gentle line shape and its curvature changes little, and its characteristics are almost the same as that of a circular curve. Moreover, a parabolic curve is much more convenient than a circular curve in design and calculation, so it is more common to use a parabolic curve as a vertical curve, as shown in Figure 4.

As shown in Figure 4, in the xoy coordinate system, the general equation of a quadratic parabola is the following equation:

$$
y=\frac{1}{2 k} x^{2}+A x
$$

At any point $\mathrm{P}$ on the vertical curve, the slope can be expressed as the following equation:

$$
i_{p}=\frac{d y}{d x}=\frac{x}{k}+A
$$

The radius of curvature at any point on a parabola can be expressed as the following equation:

$$
R=\frac{\left[1+(\mathrm{d} y / \mathrm{d} x)^{2}\right]^{(3 / 2)}}{\left(\mathrm{d}^{2} y / \mathrm{d} x^{2}\right)},
$$

where $(\mathrm{d} y / \mathrm{d} x)=i,\left(\mathrm{~d}^{2} y / \mathrm{d} x^{2}\right)=(1 / k)$, which are substituted into the above equation to obtain the following equation:

$$
R=k\left(1+i^{2}\right)^{(3 / 2)}
$$

Since $i$ is between $i_{1}$ and $i_{2}$ and both $i_{1}$ and $i_{2}$ are small, $i^{2}$ can be omitted, and then $R \approx k$. When $x=0$, equation the following equation is obtained:

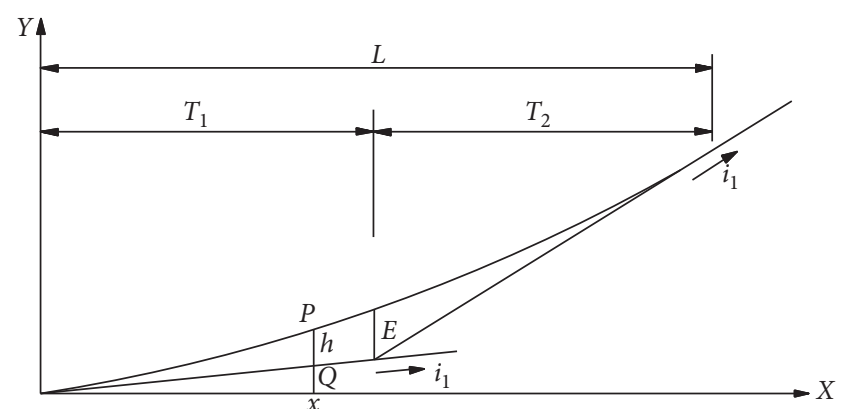

FIGURE 4: Schematic diagram of vertical curve elements.

$$
y=\frac{1}{2 R} x^{2}+i_{1} x
$$

When $x=L$ and $i=(L / K)+i_{1}=i_{2}$, equation (14) is yielded.

$$
k=\frac{L}{i_{2}-i_{1}}=\frac{L}{\omega} .
$$

From equations (12) and (14), $L=R \omega$ is obtained. Because $L=T_{1}+T_{2}$, according to $y$ at the end point of the vertical curve in Figure 4 (at this point $x=L=T_{1}+T_{2}$ ), the following equation is established:

$$
\frac{\left(T_{1}+T_{2}\right)^{2}}{2 R}+i_{1}\left(T_{1}+T_{2}\right)=T_{1} i_{1}+T_{2} i_{2} .
$$

Equation (16) can be obtained by solving equation (15) with $L=T_{1}+T_{2}=R \omega$ and $T_{1}=T_{2}$.

$$
T=\frac{L}{2}=\frac{R \omega}{2} \text {. }
$$

From $h=P Q=y_{P}-y_{Q}=\left(x^{2} / 2 R\right)+i_{1} x-i_{1} x$, the following equation can be derived:

$$
h=\frac{x^{2}}{2 R}
$$


where $x$ is the horizontal distance from any point on the vertical curve to the beginning and end points of the vertical curve.

\subsection{The Minimum Design Radius and Minimum Design} Length of the Vertical Curves of Superhighways. The Technical Standard for Highway Engineering (JTG B01-2014) and the Highway Route Design Specification (JTG D20-2006) restrict the minimum design radius and minimum design length of vertical curves. Because of the different characteristics of vehicles while driving along convex and concave vertical curves and various factors such as vehicle force, vibration, and driver horizon, the design parameters of convex and concave vertical curves are different.

In the longitudinal profile design of a superhighway, the vertical curve is constrained by many factors, among which three main factors determine the minimum radius and length of a vertical curve.

5.3.1. Shock Mitigation. While a car is driven along a vertical curve, it produces a radial centrifugal force. The centrifugal force along a concave vertical curve is represented as excess weight, and that along a convex vertical curve is represented as weightlessness. When these phenomena of excess weight and weightlessness reached a certain degree, passengers will become uncomfortable. At the same time, this also has adverse effects on the suspension system of the car, especially at the bottom of a concave curve, which may cause damage to the suspension system or a tire blowout. Therefore, in determining the radius of a vertical curve, the centrifugal acceleration must be controlled. The centrifugal acceleration of a vehicle while traveling along a rigid curve can be expressed by the following equation:

$$
a=\frac{v^{2}}{R}\left(\frac{\mathrm{m}}{\mathrm{s}^{2}}\right) \text {. }
$$

When $v(\mathrm{~m} / \mathrm{s})$ is replaced with $V(\mathrm{~km} / \mathrm{h})$, the following equation is produced:

$$
R=\frac{V^{2}}{13 a}(\mathrm{~m})
$$

Experimental results show that the reasonable range of the centrifugal acceleration $(a)$ is from $0.5 \mathrm{~m} / \mathrm{s}^{2}$ to $0.7 \mathrm{~m} / \mathrm{s}^{2}$. However, to further reduce the discomfort caused by shocks and vibrations at the bottom of concave curves and satisfy the requirements of visual smoothness, the Technical Standard for Highway Engineering (JTG b01-2014) of China has established the minimum radius of a concave vertical curve accordingly, and the centrifugal acceleration $(a)$ is approximately $0.278 \mathrm{~m} / \mathrm{s}^{2}$, while the calculation is conducted with the following equation:

$$
R_{\min }=\frac{V^{2}}{3.6}, \text { or, } L_{\min }=\frac{V^{2} \omega}{3.6} \text {. }
$$

5.3.2. Requirements of the Travel Time. Because the radius of a vertical curve generally is large and the slope angle $\omega$ is small, the length of a vertical curve is generally short. When a car transitions from a straight slope to a vertical curve that is too short while driving at a high speed, the driver will have the illusion that the slope changes rapidly and passengers may also feel uncomfortable. Based on the analysis above, in the design of a vertical curve, the shortest driving time along a vertical curve should not be too short. According to experiences in China and abroad, the driving time of a vehicle along a vertical curve cannot be shorter than 3 seconds, and then the shortest length of a vertical curve can be expressed as the following equation:

$$
L_{\min }=\frac{V}{3.6} t=\frac{V}{1.2} \text {. }
$$

5.3.3. Requirements of the Sight Distance. When a car is driven along a convex vertical curve with too small radius, the line of sight of drivers will be blocked by the road on the slope top, thus decreasing the sight distance. When a car is driven along a concave vertical curve with a small radius, there will also be the problem of an insufficient sight distance. At this time, the line of sight of drivers will be blocked by the road at the bottom of the slope and the road of the uphill section ahead. Especially for highways in areas with high topographic relief, in addition to the sight distance problem, when driving at night, the front lights are too close, which seriously affects the driving speed and safety; if there are overpasses, door-type traffic signs and advertisement billboards above a superhighway are located just above a concave vertical curve and they will also affect the line of sight of drivers. Based on the analysis above, the minimum radius and minimum length of vertical curves of superhighways must be limited in consideration of a safe sight distance.

5.4. The Minimum Radius and Length of Convex Vertical Curves of Superhighways. The minimum length of a convex vertical curve of a superhighway is mainly established to satisfy the requirements of the stopping sight distance. According to the relationship between the length $L$ of a vertical curve and the stopping sight distance $S_{\mathrm{T}}$, the calculation method is divided into two cases, i.e., $L<S_{T}$ and $L \geq S_{T}$.

$L<S_{T}$ is shown in Figure 5 .

If $h_{1}=\left(d_{1}^{2} / 2 R\right)-\left(t_{1}^{2} / 2 R\right)$, then $d_{1}=\sqrt{2 R h_{1}+t_{1}^{2}}$ and if $h_{2}=\left(d_{2}^{2} / 2 R\right)-\left(t_{2}^{2} / 2 R\right)$, then $d_{2}=\sqrt{2 R h_{2}+t_{2}^{2}}$, where $R$ is the radius of the vertical curve $(\mathrm{m}), h_{1}$ is the height of the sight line of the driver, i.e., the height of the eyes, with $h_{1}=$ $1.2 \mathrm{~m}$, and $h_{2}$ is the height of an obstacle, namely, $h_{2}=0.1 \mathrm{~m}$. Since $t_{1}=d_{1}-l=\sqrt{2 R h_{1}+t_{1}^{2}}-l$, then $t_{1}=\left(R h_{1} / l\right)-(l / 2)$. Sincet $_{2}=d_{2}-(L-l)=\sqrt{2 R h_{2}+t_{2}^{2}}-(L-l)$, then $t_{2}=$ $\left(R h_{2} / L-l\right)-(L-l / 2)$.

Therefore, the sight distance length $S_{T}=t_{1}+L+t_{2}=\left(R h_{1} / l\right)+(L / 2)+\left(R h_{2} / L-l\right)$.

Let $\left(\mathrm{d} S_{T} / \mathrm{d} l\right)=0$, and solve the equation to derive $l=\left(\sqrt{h_{1}} /\left(\sqrt{h_{1}}+\sqrt{h_{2}}\right)\right) L$, which is substituted in the above equation to define the following equations: 


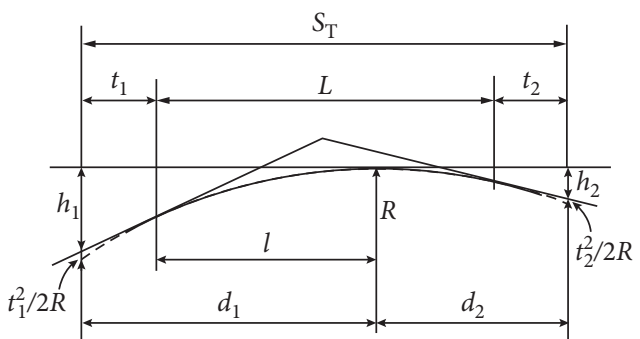

Figure 5: Calculation scheme of a convex vertical curve $\left(L<S_{T}\right)$.

$$
\begin{aligned}
& S_{T}=\frac{R}{L}\left(\sqrt{h_{1}}+\sqrt{h_{2}}\right)^{2}+\frac{L}{2}=\frac{\left(\sqrt{h_{1}}+\sqrt{h_{2}}\right)^{2}}{\omega}+\frac{L}{2}, \\
& L_{\min }=2 S_{T}-\frac{2\left(\sqrt{h_{1}}+\sqrt{h_{2}}\right)^{2}}{\omega}=2 S_{T}-\frac{4}{\omega} .
\end{aligned}
$$

$L \geq S_{T}$ is shown in Figure 6 .

If $h_{1}=\left(d_{1}^{2} / 2 R\right)$, then $d_{1}=\sqrt{2 R h_{1}}$. If $h_{2}=\left(d_{2}^{2} / 2 R\right)$, then $d_{2}=\sqrt{2 R h_{2}}$. According to the method above, equations (24) and (25) are obtained.

$$
S_{T}=d_{1}+d_{2}=\sqrt{2 R}\left(\sqrt{h_{1}}+\sqrt{h_{2}}\right) \text {, or, } S_{T}=\sqrt{\frac{2 L}{\omega}}\left(\sqrt{h_{1}}+\sqrt{h_{2}}\right),
$$

$L_{\min }=\frac{S_{T}^{2} \omega}{2\left(\sqrt{h_{1}}+\sqrt{h_{2}}\right)^{2}}=\frac{S_{T}^{2} \omega}{4}$.

The two situations above are compared.

Let $\Delta L=\left(S_{T}^{2} \omega / 4\right)-2 S_{T}+(4 / \omega)$, and since $(\omega / 4)>0$, the quadratic parabolic equation for $S_{\mathrm{T}}$ is open upward, and the discriminant is calculated with the following equation:

$$
\Delta=(-2)^{2}-4 \times \frac{\omega}{4} \times\left(\frac{4}{\omega}\right)=4-4=0 .
$$

Clearly, $\Delta L \geq 0$, and the result calculated by equation (25) is larger than that by equation (23); hence, equation (25) should be used as an effective control.

According to the three key limit factors, weightlessness at the top of the convex vertical curve, driving time along the vertical curve, and sight distance near the top of the slope, the minimum radius and minimum length of a convex vertical curve can be calculated at different design speeds, as summarized in Table 12.

Table 12 indicates that the general minimum radius stipulated in the technical standards of highway engineering is 1.5 2.0 times the minimum radius limit. The standard also requires that the radius of a vertical curve should be larger than the general minimum radius whenever possible. The minimum length of a vertical curve is equivalent to the distance traversed by a vehicle driving 3 seconds at the design speed at each highway level, which can be calculated with equation (21).

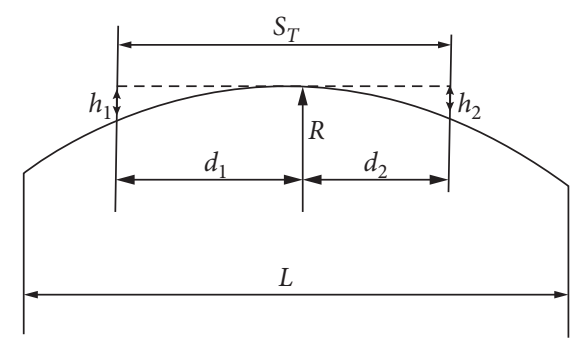

FIgURE 6: Calculation scheme of convex a vertical curve $\left(L \geq S_{T}\right)$.

Through the analysis and calculation above, the minimum radius and minimum length of a convex vertical curve of a superhighway are listed in Table 13.

5.5. Headlight Irradiation Distance Requirements. The minimum length of a concave vertical curve of a superhighway must meet the requirements of the lighting and sight distances. First, in order to ensure safe driving at night, headlights should illuminate a long enough distance in front; second, it should be ensured that there is a long enough sight distance for driving under overpass bridges and door-type signs.

According to the relationship between the vertical curve length $L$ and the stopping sight distance $S_{\mathrm{T}}$, the calculation method of the headlight irradiation distance is also divided into two situations, namely, $L<S_{T}$ and $L \geq S_{T}$. $L<S_{T}$ and is shown in Figure 7.

Since $S_{T}=L+l$ and $l=S_{T}-L$, we can obtain the following equation:

$$
h+S_{T} \operatorname{tg} \delta=\frac{(L+l)^{2}}{2 R}-\frac{l^{2}}{2 R}=\frac{\omega\left(2 S_{T}-L\right)}{2} .
$$

This equation is solved to derive the following equation:

$$
L_{\min }=2\left(S_{T}-\frac{h+S_{T} \tan \delta}{\omega}\right),
$$

where $S_{T}$ is the stopping sight distance, $m$; $h$ is the headlight height, with $h=0.75 \mathrm{~m}$; and $\delta$ is the front light beam diffusion angle, with $\delta=1.5^{\circ} . L \geq S_{T}$ is shown in Figure 8 .

Equations (29) and (30) can be obtained from Figure 8.

$$
\begin{aligned}
h+S_{T} \operatorname{tg} \delta & =\frac{S_{T}^{2}}{2 R}=\frac{S_{T}^{2} \omega}{2 L}, \\
L_{\min } & =\frac{S_{T}^{2} \omega}{2\left(h+S_{T} \operatorname{tg} \delta\right)} .
\end{aligned}
$$

Known data can be substituted into the equation above, and the following equation is generated:

$$
L_{\min }=\frac{S_{T}^{2} \omega}{1.5+0.0524 S_{T}} .
$$

Similar to the previous calculation method of convex vertical curves, the calculation result of equation (31) is 
TABLE 12: The minimum radius and length of a convex vertical curve of an ordinary highway.

\begin{tabular}{|c|c|c|c|c|c|c|c|}
\hline \multirow[b]{2}{*}{$\begin{array}{l}\text { Design } \\
\text { speed } \\
(\mathrm{km} / \mathrm{h})\end{array}$} & \multirow[b]{2}{*}{$\begin{array}{l}\text { Stopping sight } \\
\text { distance } S_{T} \\
(\mathrm{~m})\end{array}$} & \multirow[b]{2}{*}{$\begin{array}{l}\text { Impact mitigation } \\
L_{\min }=\left(V^{2} \omega / 3.6\right)\end{array}$} & \multirow[b]{2}{*}{$\begin{array}{l}\text { Lighting distance } \\
L_{\min }=\left(S_{T}^{2} \omega / 4\right)\end{array}$} & \multirow[b]{2}{*}{$\begin{array}{l}\text { Adopted } \\
\text { value } L_{\min }\end{array}$} & \multicolumn{3}{|c|}{ Value specified in the standard } \\
\hline & & & & & $\begin{array}{l}\text { Ultimate } \\
\text { minimum } \\
\text { radius }(\mathrm{m})\end{array}$ & $\begin{array}{l}\text { General } \\
\text { minimum } \\
\text { radius }(\mathrm{m})\end{array}$ & $\begin{array}{l}\text { Minimum length } \\
\text { of the vertical } \\
\text { curve }(\mathrm{m})\end{array}$ \\
\hline 120 & 210 & $4000 \omega$ & $11025 \omega$ & $11000 \omega$ & 11000 & 17000 & 100 \\
\hline 100 & 160 & $2778 \omega$ & $6400 \omega$ & $6500 \omega$ & 6500 & 10000 & 85 \\
\hline 80 & 110 & $1778 \omega$ & $3025 \omega$ & $3000 \omega$ & 3000 & 4500 & 70 \\
\hline 60 & 75 & $1000 \omega$ & $1406 \omega$ & $1400 \omega$ & 1400 & 2000 & 50 \\
\hline 40 & 40 & $444 \omega$ & $400 \omega$ & $450 \omega$ & 450 & 700 & 35 \\
\hline 30 & 30 & $250 \omega$ & $225 \omega$ & $250 \omega$ & 250 & 400 & 25 \\
\hline 20 & 20 & $111 \omega$ & $100 \omega$ & $100 \omega$ & 100 & 200 & 20 \\
\hline
\end{tabular}

TABle 13: The minimum radius and length of a convex vertical curve of a superhighway.

\begin{tabular}{|c|c|c|c|c|c|c|c|}
\hline \multirow[b]{2}{*}{$\begin{array}{l}\text { Design } \\
\text { speed } \\
(\mathrm{km} / \mathrm{h})\end{array}$} & \multirow[b]{2}{*}{$\begin{array}{l}\text { Stopping sight } \\
\text { distance } S_{T} \\
(\mathrm{~m})\end{array}$} & \multirow[b]{2}{*}{$\begin{array}{l}\text { Impact mitigation } \\
L_{\min }=\left(V^{2} \omega / 3.6\right)\end{array}$} & \multirow[b]{2}{*}{$\begin{array}{l}\text { Lighting distance } \\
L_{\min }=\left(S_{T}^{2} \omega / 4\right)\end{array}$} & \multirow[b]{2}{*}{$\begin{array}{l}\text { Adopted } \\
\text { value } L_{\min }\end{array}$} & \multicolumn{3}{|c|}{ Recommended value } \\
\hline & & & & & $\begin{array}{l}\text { Ultimate } \\
\text { minimum } \\
\text { radius }(\mathrm{m})\end{array}$ & $\begin{array}{l}\text { General } \\
\text { minimum } \\
\text { radius }(\mathrm{m})\end{array}$ & $\begin{array}{l}\text { Minimum length } \\
\text { of the vertical } \\
\text { curve }(\mathrm{m})\end{array}$ \\
\hline 180 & 360 & $9000 \omega$ & $32400 \omega$ & $32000 \omega$ & 20000 & 31000 & 145 \\
\hline 160 & 310 & $7111 \omega$ & $24025 \omega$ & $24000 \omega$ & 17000 & 26000 & 130 \\
\hline 140 & 260 & $5444 \omega$ & $16900 \omega$ & $17000 \omega$ & 14000 & 21000 & 115 \\
\hline 120 & 210 & $4000 \omega$ & $11025 \omega$ & $11000 \omega$ & 11000 & 17000 & 100 \\
\hline 100 & 160 & $2778 \omega$ & $6400 \omega$ & $6000 \omega$ & 6500 & 10000 & 85 \\
\hline
\end{tabular}

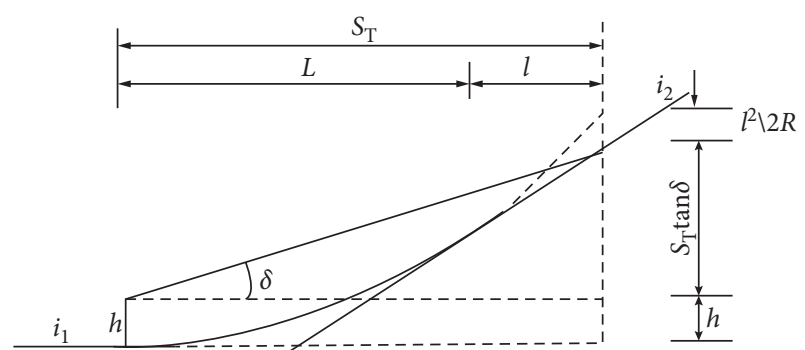

FIgURE 7: Distance of headlight irradiation $\left(L<S_{T}\right)$.

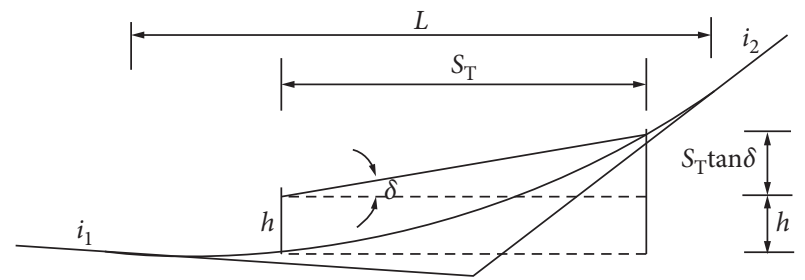

FIgURE 8: Vehicle headlight irradiation distance $\left(L \geq S_{T}\right)$.

larger than that of equation (28). Therefore, the calculation result of equation (31) should be taken as the design basis.

5.6. Sight Distance Requirements When There Is an Obstacle above the Concave Vertical Curve. $L \geq S_{T}$ is shown in Figure 9.

Equations (32)-(35) can be obtained by analyzing Figure 9.

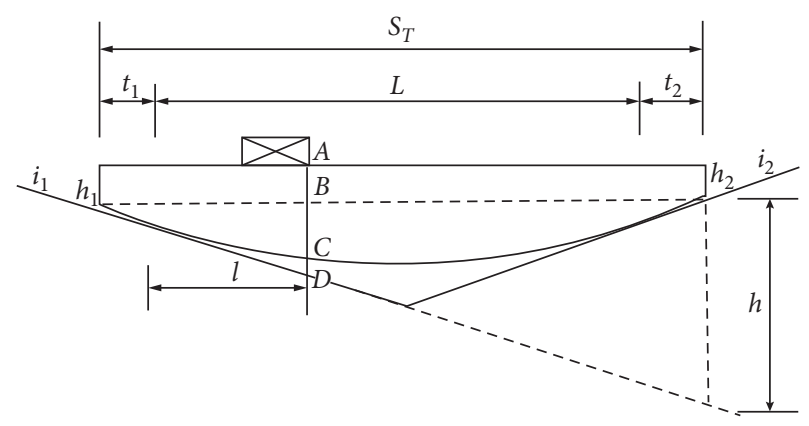

Figure 9: Sight distance under an overpass $\left(L<S_{T}\right)$.

$$
\begin{aligned}
h_{0} & =\frac{\left(L+t_{2}\right)^{2}}{2 R}-\frac{t_{2}^{2}}{2 R}, \\
A B & =h_{1}+\frac{h_{2}-h_{1}}{S_{T}}\left(t_{1}+l\right), \\
B D & =h_{0} \frac{t_{1}+l}{S_{T}}=\left[\frac{\left(L+t_{2}\right)^{2}}{2 R}-\frac{t_{2}^{2}}{2 R}\right] \frac{t_{1}+l}{S_{T}}, \\
C D & =\frac{l^{2}}{2 R} .
\end{aligned}
$$

Since $S_{T}=t_{1}+L+t_{2}$, then $t_{2}=S_{T}-t_{1}-L$, and the following equation is yielded: 


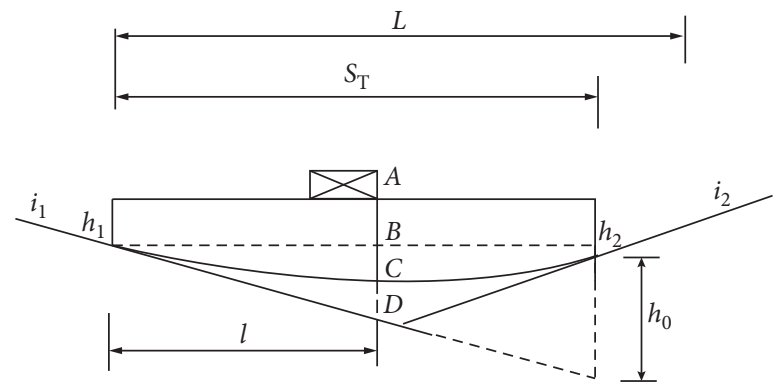

Figure 10: Sight distance under the overpass $(L \geq S T)$.

$$
h=A B+B D-C D=h_{1}+\frac{h_{2}-h_{1}}{S_{T}}\left(t_{1}+l\right)+\frac{L\left(l+t_{1}\right)}{2 R S_{T}}\left(2 S_{T}-2 t_{1}-L\right)-\frac{l^{2}}{2 R} .
$$

The condition of $\mathrm{d} h / \mathrm{d} l=0$ is used to solve $l$, which is substituted into the above equation, and after rearrangement, we can produce the following equation:

$$
h_{\text {max }}=h_{1}+\frac{1}{2 R S_{T}^{2}}\left[2 S_{T} t_{1}+R\left(h_{2}-h_{1}\right)+\frac{L}{2}\left(2 S_{T}-2 t_{1}-L\right)\right] \bullet\left[R\left(h_{2}-h_{1}\right)+\frac{L}{2}\left(2 S_{T}-2 t_{1}-L\right)\right] \text {. }
$$

The condition of $\mathrm{d} h_{\max } / \mathrm{d} t_{1}=0$ is used to solve $t_{1}$, which is substituted into the above equation; after rearrangement, the following equation is acquired:

$$
h_{\max }=h_{1}+\frac{\left[2 R\left(h_{2}-h_{1}\right)+\left(2 S_{T}+L\right)\right]^{2}}{8 R L\left(2 S_{T}-L\right)} .
$$

Equation (38) is solved, and we can derive the following equation:

$$
h_{\max }=2 S_{T}-\frac{4 h_{\max }}{\omega}\left[1-\frac{h_{2}+h_{1}}{2 h_{\max }}+\sqrt{\left(1-\frac{h_{1}}{h_{\max }}\right)\left(1-\frac{h_{2}}{h_{\max }}\right)}\right],
$$

where $h_{\max }$ is the design clearance under the bridge, with $h_{\max }=4.5 \mathrm{~m} ; h_{1}$ is the visual height of the driver, with $h_{1}=1.5 \mathrm{~m}$; and $h_{2}$ is the obstacle height, with $h_{2}=0.75 \mathrm{~m}$.

Known data can be substituted into equation (39), and equation (40) is obtained.

$$
L_{\max }=2 S_{T}-\frac{26.92}{\omega}
$$

$L \geq S_{\mathrm{T}}$ is shown in Figure 10 .

Equations (41)-(45) can be obtained from analysis of Figure 10.

$$
\begin{aligned}
h_{0} & =\frac{S_{T}^{2}}{2 R}, \\
A B & =h_{1}+\frac{h_{2}-h_{1}}{S_{T}} l, \\
B D & =h_{0} \frac{l}{S_{T}}=\frac{S_{T}}{2 R} l,
\end{aligned}
$$

$$
\begin{aligned}
& C D=\frac{l^{2}}{2 R}, \\
& A C=h=h_{1}+\frac{h_{2}-h_{1}}{S_{T}} l+\frac{S_{T}}{2 R} l-\frac{l^{2}}{2 R},
\end{aligned}
$$

where $d h / d l=0$ is used to solve $l$, which can be substituted into the above equation, and through rearrangement, the following equations are yielded:

$$
\begin{aligned}
& h_{\max }=h_{1}+\frac{1}{2 R}\left[\frac{R\left(h_{2}-h_{1}\right)}{S_{T}}+\frac{S_{T}}{2}\right]^{2}, \\
& L_{\min }=\frac{S_{T}^{2} \omega}{\left[\sqrt{2\left(h_{\max }-h_{1}\right)}+\sqrt{2\left(h_{\max }-h_{2}\right)}\right]^{2}} .
\end{aligned}
$$

Known data are substituted into equation (47), and the following equation is derived:

$$
L_{\min }=\frac{S_{T}^{2} w}{26.92} .
$$

Similar to the previous calculation and comparison method of convex vertical curves, the above two equations should be compared in the same way, and equation (48) should be regarded as the effective control. The minimum radius of a concave vertical curve can be calculated according to the three key limiting factors that affect the design minimum radius of vertical curves of superhighways, and the results are listed in Table 14.

The most unfavourable situation contained in the above table for a concave vertical curve is the impact of radial centrifugal forces. Therefore, equation (48) should be used as 
TABLE 14: The minimum radius of a concave vertical curve of an ordinary highway.

\begin{tabular}{|c|c|c|c|c|c|c|c|c|}
\hline \multirow[b]{2}{*}{$\begin{array}{l}\text { Design } \\
\text { speed } \\
(\mathrm{km} / \mathrm{h})\end{array}$} & \multirow[b]{2}{*}{$\begin{array}{l}\text { Stopping } \\
\text { sight } \\
\text { distance } \\
S_{T}(\mathrm{~m})\end{array}$} & \multirow[b]{2}{*}{$\begin{array}{c}\text { Impact } \\
\text { mitigation } L_{\min }= \\
\left(V^{2} \omega / 3.6\right)\end{array}$} & \multirow[b]{2}{*}{$\begin{array}{c}\text { Lighting distance } \\
L_{\min }=\left(S_{T}^{2} \omega /\left(1.5+0.0524 S_{T}\right)\right)\end{array}$} & \multirow[b]{2}{*}{$\begin{array}{c}\text { Sight distance } \\
\text { under the bridge } \\
L_{\min }=\left(S_{T}^{2} / 26.92\right)\end{array}$} & \multirow[b]{2}{*}{$\begin{array}{l}\text { Adopted } \\
\text { value } \\
L_{\min }\end{array}$} & \multicolumn{3}{|c|}{ Value specified in the standard } \\
\hline & & & & & & $\begin{array}{l}\text { Ultimate } \\
\text { minimum } \\
\text { radius }(\mathrm{m})\end{array}$ & $\begin{array}{c}\text { General } \\
\text { minimum } \\
\text { radius }(\mathrm{m})\end{array}$ & $\begin{array}{l}\text { Minimum } \\
\text { length of } \\
\text { the vertical } \\
\text { curve }(\mathrm{m})\end{array}$ \\
\hline 120 & 210 & $4000 \omega$ & $3527 \omega$ & $1638 \omega$ & $4000 \omega$ & 4000 & 6000 & 100 \\
\hline 100 & 160 & $2778 \omega$ & $2590 \omega$ & $951 \omega$ & $3000 \omega$ & 3000 & 4500 & 85 \\
\hline 80 & 110 & $1778 \omega$ & $1666 \omega$ & $449 \omega$ & $2000 \omega$ & 2000 & 3000 & 70 \\
\hline 60 & 75 & $1000 \omega$ & $1036 \omega$ & $209 \omega$ & $1000 \omega$ & 1000 & 1500 & 50 \\
\hline 40 & 40 & $444 \omega$ & $445 \omega$ & $59 \omega$ & $450 \omega$ & 450 & 700 & 35 \\
\hline 30 & 30 & $250 \omega$ & $293 \omega$ & $33 \omega$ & $250 \omega$ & 250 & 400 & 25 \\
\hline 20 & 20 & $111 \omega$ & $157 \omega$ & $15 \omega$ & $100 \omega$ & 100 & 200 & 20 \\
\hline
\end{tabular}

TABLE 15: The minimum radius of a concave vertical curve of a superhighway.

\begin{tabular}{|c|c|c|c|c|c|c|c|c|}
\hline \multirow[b]{2}{*}{$\begin{array}{l}\text { Design } \\
\text { speed } \\
(\mathrm{km} / \mathrm{h})\end{array}$} & \multirow[b]{2}{*}{$\begin{array}{l}\text { Stopping } \\
\text { sight } \\
\text { distance } \\
S_{T}(\mathrm{~m})\end{array}$} & \multirow[b]{2}{*}{$\begin{array}{c}\text { Impact } \\
\text { mitigation } L_{\min }= \\
\left(V^{2} \omega / 3.6\right)\end{array}$} & \multirow[b]{2}{*}{$\begin{array}{c}\text { Lighting distance } \\
L_{\min }=\left(S_{T}^{2} \omega /\left(1.5+0.0524 S_{T}\right)\right)\end{array}$} & \multirow[b]{2}{*}{$\begin{array}{l}\text { Sight distance } \\
\text { under the bridge } \\
L_{\min }=\left(S_{T}^{2} / 26.92\right)\end{array}$} & \multirow[b]{2}{*}{$\begin{array}{l}\text { Adopted } \\
\text { value } \\
L_{\min }\end{array}$} & \multicolumn{3}{|c|}{ Value specified in the standard } \\
\hline & & & & & & $\begin{array}{l}\text { Ultimate } \\
\text { minimum } \\
\text { radius }(\mathrm{m})\end{array}$ & $\begin{array}{l}\text { General } \\
\text { minimum } \\
\text { radius }(\mathrm{m})\end{array}$ & $\begin{array}{l}\text { Minimum } \\
\text { length of } \\
\text { the vertical } \\
\text { curve }(\mathrm{m})\end{array}$ \\
\hline 180 & 360 & $9000 \omega$ & $6364 \omega$ & $4814 \omega$ & 7000 & 7000 & 10500 & 145 \\
\hline 160 & 310 & $7111 \omega$ & $5416 \omega$ & $3570 \omega$ & 6000 & 6000 & 9000 & 130 \\
\hline 140 & 260 & $5444 \omega$ & $4470 \omega$ & $2511 \omega$ & 5000 & 5000 & 7500 & 115 \\
\hline 120 & 210 & $4000 \omega$ & $3527 \omega$ & $1638 \omega$ & 4000 & 4000 & 6000 & 100 \\
\hline 100 & 160 & $2778 \omega$ & $2590 \omega$ & $951 \omega$ & 3000 & 3000 & 4500 & 85 \\
\hline
\end{tabular}

the effective control. The general minimum radius of ordinary highways stipulated in the Technical Standards for Highway Engineering is 1.5 2.0 times the minimum radius. The calculation method of the minimum length of a concave vertical curve is the same as that of a convex vertical curve.

According to the analysis and calculation above, the minimum radius of a concave curve of a superhighway is listed in Table 15.

\section{Conclusion}

On the basis of conducting force analysis of a car while it is driven, considering the visual characteristics of drivers, vehicle climbing performance, and braking performance, combined with the influence of road design parameters on driving safety and comfort, the design parameters of the longitudinal profile of a superhighway were calculated. Specific conclusions are summarized as follows:

(1) When the design speed is $180 \mathrm{~km} / \mathrm{h}, 160 \mathrm{~km} / \mathrm{h}$, and $140 \mathrm{~km} / \mathrm{h}$, the maximum longitudinal slope of a superhighway is $2.50 \%, 2.25 \%$, and $2.00 \%$, respectively, and the minimum longitudinal slope ranges from $0.3 \%$ to $0.5 \%$, which can not only satisfy the requirements of the vehicle climbing performance but also the visual requirements of the driver and the requirements of road drainage.

(2) When the design speed is $180 \mathrm{~km} / \mathrm{h}, 160 \mathrm{~km} / \mathrm{h}$, and $140 \mathrm{~km} / \mathrm{h}$, the minimum slope length of a superhighway is $450 \mathrm{~m}, 400 \mathrm{~m}$, and $350 \mathrm{~m}$, respectively, and the maximum slope length ranges from $900 \mathrm{~m}$ to
$1100 \mathrm{~m}$ according to the vertical slope, which not only satisfies the vehicle climbing performance requirements but also the braking performance requirements.

(3) When the design speed is $180 \mathrm{~km} / \mathrm{h}, 160 \mathrm{~km} / \mathrm{h}$. and $140 \mathrm{~km} / \mathrm{h}$, the minimum length of a vertical curve is $145 \mathrm{~m}, 130 \mathrm{~m}$, and $115 \mathrm{~m}$, respectively, which not only meets the visual range requirements of drivers but also enhances driving comfort.

At present, research on superhighways is still in its infancy in China, and the depth and breadth of research must be improved. We expect that many researchers and engineers will work together to contribute to the development of superhighways in China.

\section{Data Availability}

The data used to support the findings of this study are available from corresponding author upon request (e-mail: hymjob@nefu.edu.cn).

\section{Conflicts of Interest}

The authors declare that they have no conflicts of interest regarding the publication of this paper.

\section{Acknowledgments}

The authors thank the director of the laboratory, Li Shaoyan, for providing the experimental equipment and Professor Cheng Yang of the University of Wisconsin for the 
calculation method. The authors would like to thank the teachers and graduate students of the transportation research center of Northeast Forestry University for their help. This work was supported by the Natural Science Foundation of Heilongjiang Province, China, grant no. LH2019E004 and the National Natural Science Foundation of China, grant no. 71771047.

\section{References}

[1] A. van Benthem, "What is the optimal speed limit on freeways?" Journal of Public Economics, vol. 124, pp. 44-62, 2015.

[2] B. Kuhn, K. Balke, R. Brydia et al., "Evaluation of variable speed limit pilot projects for Texas department of transportation," Transportation Research Procedia, vol. 15, pp. 676-693, 2016.

[3] F. La Torre, M. Meocci, and A. Nocentini, "Safety effects of automated section speed control on the Italian motorway network," Journal of Safety Research, vol. 69, pp. 115-123, 2019.

[4] M. Hartmann, P. Vortisch, and B. J. Schroeder, "A German approach to freeway facility evaluation," Transportation Research Record: Journal of the Transportation Research Board, vol. 2483, no. 1, pp. 66-73, 2015.

[5] People's Communications Press, Ministry of Communications of the People's Republic of China, Highway Engineering Technical Standard (Trial), People's Communications Press, Beijing, China, 1951.

[6] Y. He and Y. Pei, "Feasibility demonstration and necessity analysis on superhighway," Highway, vol. 1, no. 1, pp. 8-12, 2016.

[7] Y. He and Y. Pei, "Research on highway speed guidance system through experiment and simulation," Highway, vol. 59, no. 6, pp. 179-182, 2014.

[8] Y. He, Research on Safety Support and Economy Evaluation of Superhighway, Northeast forestry university, Harbin, China, 2017.

[9] Y. He and B. Ding, "Environmental and economic evaluation of superhighway based on travel cost," EBSCO, vol. 107, pp. 4793-4801, 2018.

[10] Y. H. P. He, "Research on super highway and it's capacity'," Journal of Heilongjiang Institute of Engineering, vol. 31, no. 4, pp. 8-12, 2017.

[11] F. Chen and X. Peng, "Research on superhighway development based on SWOT analysis," Science and Technology Vision, vol. 3, no. 5, pp. 139-140, 2018.

[12] Y. Zhao, H. Mao, and J. Liu, "Research on safety flat-curve radius of superhighway," Western Transportation Technology, no. 2, pp. 159-163, 2019.

[13] F. Chen, B. Dong, X. Ma, and S. Chen, "Investigating the differences of single- and multi-vehicle accident probability using mixed logit model," Journal of Advanced Transportation, vol. 2018, Article ID 2702360, 9 pages, 2018.

[14] C. Feng and S. Chen, "Injury severities of truck drivers in single- and multi-vehicle accidents on rural highway," Accident Analysis and Prevention, vol. 43, no. 5, pp. 1677-1688, 2011.

[15] M. Zhang, X. Tang, L. Guo, N. Li, and J. Cheng, Comparison on Main Parameters of Highway Geometric Design between China and Foreign Countries, American Society of Civil Engineers, Reston, VA, USA, pp. 2108-2122, 2019.

[16] D. B. Fambro, K. Fitzpatrick, and R. J. Koppa, "New stopping sight distance model for use in highway geometric design,"
Transportation Research Record: Journal of the Transportation Research Board, vol. 1701, no. 1, pp. 1-8, 2000.

[17] M.-W. Kang, S. Shariat, and M. K. Jha, "New highway geometric design methods for minimizing vehicular fuel consumption and improving safety," Transportation Research Part C: Emerging Technologies, vol. 31, pp. 99-111, 2013.

[18] R. J. Porter, E. T. Donnell, and J. M. Mason, "Geometric design, speed, and safety," Transportation Research Record: Journal of the Transportation Research Board, vol. 2309, no. 1, pp. 39-47, 2012.

[19] M. Castro and C. De Santos-Berbel, "Spatial analysis of geometric design consistency and road sight distance," International Journal of Geographical Information Science, vol. 29, no. 12, pp. 2061-2074, 2015.

[20] C. Dong, S. S. Nambisan, S. H. Richards, and Z. Ma, “Assessment of the effects of highway geometric design features on the frequency of truck involved crashes using bivariate regression," Transportation Research Part A: Policy and Practice, vol. 75, pp. 30-41, 2015.

[21] Y. Xiao, Test and Research for Speed Raising on Existing Railways in China, China Academy of Railway Sciences, Beijing, China, 2000.

[22] P. Yin, Z. Lin, and B. Prideaux, “The impact of high-speed railway on tourism spatial structures between two adjoining metropolitan cities in China: Beijing and Tianjin," Journal of Transport Geography, vol. 80, Article ID 102495, 2019.

[23] G. Lin and X. Sheng, "Application and further development of Maglev transportation in China," Transportation Systems and Technology, vol. 4, no. 3, pp. 36-43, 2018.

[24] N. Hussain, Design and Construction of Sea-Crossing Bridges-A Review', Multi-Span Large Bridges, Taylor \& Francis Group, Porto, Portugal, 2015, https://www.taylorfrancis.com/.

[25] Y. He, Y. Pei, B. Ran, J. Kang, and Y. Song, "Superhighway virtual track system based on intelligent road buttons," IEEE Access, vol. 8, pp. 33419-33427, 2020.

[26] Z. Yao, L. Shen, R. Liu, Y. Jiang, and X. Yang, "A dynamic predictive traffic signal control framework in a cross-sectional vehicle infrastructure integration environment," IEEE Transactions on Intelligent Transportation Systems, vol. 21, no. 4, pp. 1455-1466, 2020. 